\title{
ONTOLOGIA E OBRA LITERÁRIA: A RESPOSTA REALISTA DE INGARDEN A HUSSERL
}

\author{
Allan J. Vieira ${ }^{*}$ \\ Universidade Federal de Santa Catarina (UFSC) \\ (iD) https://orcid.org/0000-0002-8589-858X
}

\begin{abstract}
RESUMO:
O idealismo transcendental anunciado por Husserl como idêntico à própria fenomenologia nunca deixou de ser um dos pontos mais polêmicos de sua filosofia. A esse respeito, um dos primeiros críticos da posição filosófica esposada publicamente por Husserl a partir de Ideias para uma fenomenologia pura foi seu outrora aluno Roman Ingarden. Seu denso e resoluto criticismo em relação à perspectiva idealista de Husserl é amparado por minuciosas investigações de ordem ontológica, contidas sobretudo em seu magnum opus, Controvérsia acerca da existência do mundo. Contudo, algumas das discussões aí indicadas já se faziam presentes em seu famoso escrito A obra de arte literária, de 1929. Com efeito, neste texto, que busca demarcar o estatuto ontológico das obras literárias, Ingarden já empreende análises que lhe permitem questionar alguns dos pressupostos centrais ao idealismo transcendental advogado por Husserl. A proposta do presente trabalho é apresentar algumas das noções básicas da ontologia ingardeniana, bem como sua visão acerca do modo de ser da obra literária, e tentar compreender como estes elementos se coordenam a fim de fornecer a Ingarden alguns dos elementos que lhe permitem ensaiar uma resposta realista à perspectiva de Husserl.
\end{abstract}

PALAVRAS-CHAVE: Idealismo; Realismo; Ontologia; Obra literária; Ingarden.

\section{ONTOLOGY AND THE LITERARY WORK: THE REALISTIC INGARDEN'S RESPONSE TO HUSSERL}

\author{
ABSTRACT: \\ * Doutorando em Filosofia pela Universidade Federal de Santa Catarina (UFSC), Santa \\ Catarina - Brasil. E-mail: allanjvieira@ hotmail.com.
}


The transcendental idealism announced by Husserl as identical to phenomenology itself was one of the most controversial points of his philosophy. In this respect, one of the first critics of the philosophical position espoused openly by Husserl since Ideas for a Pure Phenomenology was his old student Roman Ingarden. Its dense and resolute criticism in relation to Husserl's idealistic perspective is supported by deep ontological investigations, contained mainly in his magnum opus, Controversy over the Existence of the World. However, some of the discussions displayed there were already present in his famous writing The Literary Work of Art, from 1929. Indeed, in this text, which seeks to demarcate the ontological status of literary works, Ingarden already undertakes analyses that allow him to question some of the central assumptions of the transcendental idealism advocated by Husserl. The proposal of this work is to present some of the basic notions of Ingarden's ontology, as well as his views on the mode of being of literary work, and try to understand how these elements coordinate in order to provide to Ingarden some elements that allow him to attempt a realistic response to Husserl's position.

KEYWORDS: Idealism; Realism; Ontology; Literary work; Ingarden.

\section{Introdução}

Embora se trate de um monumental esforço em direção à elaboração de uma ontologia da obra literária, Das literarische Kunstwerk ${ }^{1}$, provavelmente a obra mais conhecida de Roman Ingarden, traz um impulso filosófico por vezes esquecido, mas que o próprio autor faz questão de destacar. Os prefácios a primeira e segunda edições dão conta das preocupações do filósofo polonês: nada menos que um dos temas centrais nas disputas do início do século XX, qual seja, o debate, herdado da modernidade, entre idealismo e realismo ${ }^{2}$. Especificamente, é contra seu antigo mestre, Edmund Husserl, que Ingarden se posiciona, conforme já o testemunhava a famosa 'Carta sobre o idealismo' de $1918^{3}$. É em oposição ao idealismo husserliano, cujo traço central seria a identificação da

\footnotetext{
${ }^{1}$ Utilizamos a tradução para o português: INGARDEN, R. A obra de arte literária. $2^{\mathrm{a}}$ ed. Tradução de A. E. Beau, M. C. Puga e J. F. Barrento. Lisboa: Fundação Calouste Gulbenkian, 1979. No corpo do texto, abreviada como $L K$.

2 "Apesar de as minhas investigações terem por tema principal a obra literária, e sobretudo a obra de arte literária, os motivos que, em última análise, me levaram a tratar este tema são de natureza filosófica geral e transcendem amplamente este assunto regional. Estão intimamente relacionados com o problema idealismo-realismo, que desde há anos me preocupa" (INGARDEN, 1979, p. 4, grifo do autor).

INGARDEN, R. The Letter to Husserl About the VI [Logical] Investigation and 'Idealism'. In: TYMIENIECKA, A.-T. (ed.). Ingardeniana: a spectrum of specialised studies establishing the field of Research. Dordrecht, Boston: D. Riedel Publishing Company, 1976, p. 419-38.
} 
totalidade do mundo como simples correlato intencional da consciência, que Ingarden reclama a inultrapassável heterogeneidade entre realidade e objetividade intencional ${ }^{4}$.

É por essa via que Das literarische Kunstwerk se insere no debate idealismo-realismo. Com efeito, nessa obra, Ingarden prepara o terreno para as distinções básicas - sobretudo, ontológico-formais - entre objetividades reais e puramente intencionais que serão desenvolvidas de modo exaustivo em sua obra máxima, Der Streit um die Existenz der Welt ${ }^{5}$. São estas distinções, tal como apresentadas em Das literarische..., que procuraremos explorar em nosso trabalho. Em geral, os estudos acerca do criticismo ingardeniano ao idealismo de Husserl permanecem embasados naquele que se tornou o texto mais conhecido de Ingarden sobre o tema, a saber, o pequeno escrito On the Motives which led Husserl to Transcendental Idealism, passando por alto os apontamentos contidos em Das literarische... Nossa exposição, por seu lado, procurará examinar este último texto. Para tanto, as discussões abaixo se darão do seguinte modo: em primeiro plano, procurar-se-á enfocar a contrariedade de Ingarden relativamente à posição de Husserl, especialmente a divergência concernente à compreensão do problema do idealismo e o método adequado para uma abordagem satisfatória. Depois, alguns conceitos da ontologia ingardeniana necessários ao entendimento das discussões contidas em Das literarische... serão expostos. Após estes apontamentos introdutórios, buscaremos indicar, de maneira sumária, alguns dos traços centrais da ontologia da obra literária proposta por Ingarden, o que tornará possível, consequentemente, assinalar os pontos que permitem ao filósofo polonês colocar em xeque algumas das teses centrais do idealismo husserliano. Ao fim, espera-se que seja possível compreender os elementos extraídos das considerações sobre a obra de arte literária que fornecem a Ingarden aquilo que ele acredita serem recursos teóricos que lhe permitirão ensaiar uma resposta realista ao idealismo transcendental proposto por Husserl.

\section{Contra o idealismo husserliano}

O primeiro ponto relevante a ser apreendido é o modo segundo o qual Ingarden compreende a questão fulcral que estabelece a órbita na qual irão se mover os elementos do debate idealismo-realismo. Trata-se do

\footnotetext{
${ }^{4} \mathrm{Na}$ carta de 1918 a Husserl, Ingarden já assinala que não pode abrir mão da diferença essencial dos modos de ser da consciência e do mundo real e afirma que, por essência, um objeto real não pode ser reduzido a mero ser intencional (INGARDEN, 1976, p. 425).

${ }^{5}$ Utilizamos a tradução do primeiro volume para o inglês: INGARDEN, R. Controversy over the existence of the world. Volume I. Translated and annotated by A. Szylewicz. Frankfurt am Main: Peter Lang Edition, 2013. As referências feitas ao segundo volume se valem da edição original: INGARDEN, R. Der Streit um die Existenz der Welt. Band 2: Formalontologie. Teil 1. Tübingen: Max Niemeyer Verlag, 1965. No corpo do texto, utilizaremos a abreviação 'Streit', mencionando o volume referido.
} 
problema acerca da existência do mundo; especificamente, a respeito de seu modo de ser e de sua relação com a consciência (INGARDEN, 2013, p. 289). A questão, afinal, não se traduz em uma dúvida sobre a existência do mundo, mas, antes, diz respeito ao modo de sua existência, bem como à sua relação com a consciência e os atos cognitivos (INGARDEN, 1975, p. 31).

Em Streit, Ingarden elabora o problema de modo mais refinado, precisando aquilo que está em jogo, embora ainda sob uma formulação provisória (que, entretanto, já indica a perspectiva ontológica de suas investigações): "A questão que nós enfrentamos é ou aceitar um mundo real que seja 'existencialmente independente' da consciência pura, ou um que seja 'existencialmente dependente' dela"' (INGARDEN, 2013, p. 95, tradução nossa). Relativamente ao idealismo transcendental de Husserl, o problema é rearticulado como a redução de toda a realidade a mero correlato dos atos intencionais da consciência. Com efeito, segundo a perspectiva husserliana, o mundo real e a infinidade de objetos aí dados não seriam algo de independente, mas apenas correlatos intencionais; fora isso, um nada (HUSSERL, 2006, p. 117). No decorrer do desenvolvimento do pensamento de Husserl, essa posição apresentada em Ideias para uma fenomenologia pura não cessará de ganhar fôlego. Em Lógica formal e transcendental, tem-se a afirmação categórica de que todo ente se constitui na subjetividade; mesmo a transcendência e o sentido de ser (Seinssinn) de qualquer objeto não são mais que algo constituído no nexo das vivências da consciência pura (HUSSERL, 1969, p. 232-6). E, nas Meditações cartesianas, a transcendência volta a ser afirmada como algo constituído na consciência: todo ente, seja ele real ou ideal, estaria circunscrito aos domínios do ego transcendental (HUSSERL, 2010, p. 126-7).

Desse modo, no jogo que Husserl estabelece entre consciência e realidade, não parece haver dúvidas sobre quem dá as cartas. O resultado, conforme Ingarden (2013, p. 181), não poderia ser outro senão a afirmação de que todo objeto real não é nada além de um objeto puramente intencional, ou seja, o produto de certos atos da consciência - ou, ainda, uma criação exclusiva dos processos cognitivos (INGARDEN, 1975, p. 37). Conforme observa Mitscherling (1997, p. 49), o alvo central de Ingarden, aqui, é o conceito husserliano de constituição, segundo o qual o objeto não é algo 'em si', mas "só é o que é na sua correlação com o conhecimento possível” (HUSSERL, 2008, p. 105). Com isso, Husserl estaria assumindo uma tese metafísica que nega autonomia existencial a um mundo natural existindo 'em si' (MITSCHERLING, 1997, p. 48-9). Assim, a partir da mise en scène destes elementos, a formulação da questão acerca da existência do mundo, relativamente à posição de Husserl, ganha contornos definitivos: o problema passa a ser o de determinar "se o mundo real ou as objetividades

6 " [...] the question we face is whether to accept a real world that is 'existentially independent' of pure consciousness, or one that is 'existentially dependent' on it'. 
nele disponíveis são objetos puramente intencionais ou algo fundamentalmente diferente destes" (INGARDEN, 1965, p. 174, tradução nossa).

O método julgado adequado por Ingarden para lidar com essa pergunta também marca um afastamento relativamente a seu antigo mestre. Isso porque Ingarden vê na abordagem husserliana os ecos de um erro que remonta a Descartes e a toda a filosofia moderna: a posição do problema é derivada somente de preocupações epistemológicas, bem como as tentativas para sua solução; isto é, a partir da indubitabilidade da percepção imanente, coloca-se em causa a existência do mundo e tenta-se, consequentemente, extrair alguma confirmação sua unicamente a partir da existência do ego e de seus atos de consciência - erro que estaria à base das soluções idealistas da história da filosofia (INGARDEN, 2013, p. 30, p. 162). Ora, Husserl seguiria a mesma perspectiva ao advogar a necessidade da famosa redução fenomenológica, cuja função seria assegurar a esfera indubitável das vivências puras da consciência como o único domínio da investigação transcendental (INGARDEN, 2013, p. 40). No entanto, este ponto de partida conduziria Husserl a uma posição metafisicamente comprometida (a dependência da realidade face à consciência), resultando, então, numa transgressão dos limites autoimpostos pelo próprio procedimento da redução fenomenológica (INGARDEN, 2013, p. 187).

O ponto central é que, para Ingarden, a crux da controvérsia idealismo-realismo se constitui numa questão metafísica, e esta ordem de problemas, por sua vez, demanda uma série de clarificações preliminares de natureza ontológica (INGARDEN, 2013, p. 45, p. 86, p. 187). De acordo com a perspectiva de Ingarden, investigações ontológicas não se dirigem à existência factual de objetividades, mas analisam puras possibilidades fundadas a priori no conteúdo de determinadas ideias ${ }^{8}$ e nas relações necessárias entre elas; por sua vez, a relação entre o conteúdo das ideias e os objetos individuais correspondentes faz com que as asserções ontológicas se transformem em proposições que estabelecem os estados de coisa possíveis e necessários no domínio dos objetos individuais (INGARDEN, 2013, p. 612, p. 66-7, p. 72). A metafísica, por outro lado, adentra o domínio da existência factual, mas não investiga simples fatos 'brutos'; procura, antes, estabelecer fatos essenciais fundados na essência das entidades correspondentes, o que seria possível graças a um recurso aos resultados

\footnotetext{
7 “ "...] ob die reale Welt bzw die in ihr vorhandenen Gegenständlichkeiten rein intentionale Gegenstände oder etwas vor denselben Grundverschiedenes sind".

${ }^{8}$ As ideias, para Ingarden, são certo tipo de 'objeto geral' (INGARDEN, 2013, p. 62, nota), cuja existência, enquanto objetos universais, é tomada como mais ou menos certa (JOHANSSON, 2009, p. 66). De acordo com Wachter (2005, p. 60, p. 76), as ideias seriam entes não temporais, ideais, que possuem um conteúdo (Gehalt) no qual seriam determinadas propriedades e relações concernentes a objetos particulares subsumidos sob a ideia correspondente. Em $L K$, Ingarden afirma que há ideias que correspondem a todos os entes objetivos (INGARDEN, 1979, p. 401).
} 
alcançados nas pesquisas ontológicas. Nesse sentido, a metafísica surge como uma complementação da ontologia; e, por sua vez, tem sua preparação indispensável nesta (INGARDEN, 2013, p. 59-60, p. 80).

Desse modo, portanto, vê-se como a questão sobre a identidade ou diferença entre objetos reais e intencionais, posta por Ingarden como o problema central em relação ao idealismo husserliano, deve ter como ponto de partida para a sua resolução análises ontológicas; preocupação que se traduz na seguinte formulação: "A principal questão a surgir é se há uma distinção existencial ${ }^{9}$ entre o mundo real e a consciência pura, e, se este for o caso - de que tipo ela é"10 (2013, p. 161, tradução nossa). Ingarden busca, então, fugir de qualquer comprometimento metafísico estipulado por um ponto de partida erroneamente delimitado, bem como oferecer um modo de investigação adequado à própria natureza do problema.

Ainda no que concerne à perspectiva idealista de Husserl, segundo Mitscherling (1997, p. 83-4), três pontos surgem como centrais para as preocupações de Ingarden: (1) a negação husserliana da transcendência de um objeto 'em si', pois seu caráter transcendente é algo constituído na consciência; (2) consequentemente, todo objeto do mundo real se torna um correlato intencional; (3) os objetos intencionais, por sua vez, encontram como seu único fundamento ontológico os atos da consciência. Relativamente a estes pontos, numa primeira elaboração de uma resposta a Husserl, dois aspectos se destacam em $L K$, quais sejam, as indicações sobre a diferença fundamental entre os caracteres formais das objetividades reais e puramente intencionais e a demonstração de que a obra de arte literária, enquanto objeto puramente intencional, não pode ter como sua única base ontológica os atos de consciência (sejam do autor ou do leitor). É nesse contexto, então, que a ontologia da obra de arte literária irá indicar as primeiras diferenças básicas entre o modo de ser do mundo real e dos

\footnotetext{
${ }^{9}$ De maneira mais delimitada: trata-se de um problema ontológico-existencial, isto é, relativo ao modo de ser pertencente às objetividades em questão, de acordo com o que é prescrito pela ideia correspondente e pelas ideias de existência em geral e dos modos de ser particulares. Cf. INGARDEN, 2013, p. 87-8. Johansson (2013, p. 137-8) explicita o que entra em cena nas questões ontológico-existenciais: são investigações que visam determinar que modos de ser ou maneiras de existência são a princípio possíveis, ou seja, que não se apresentem a priori como autocontraditórias ou internamente absurdas. Obviamente, ainda se está dentro dos limites prescritos pela definição ingardeniana de ontologia, pois não se trata de asseverar a existência factual das objetividades, mas somente delimitar o modo específico de ser que lhes compete de acordo com as determinações a priori derivadas do conteúdo das ideias correspondentes. Os problemas abarcados pela ontologia ainda podem ser ontológico-formais (tratam das estruturas gerais de um objeto que sejam determinadas $a$ priori por sua forma - se é uma coisa, um processo, uma relação etc.) ou ontológicomateriais (consideram as determinações materiais ou qualitativas - o 'preenchimento' de uma forma), de acordo com a ideia correspondente e seu conteúdo (INGARDEN, 2013, p. 87-9).

10 "The foremost question to arise is whether there is an existential distinction between the real world and pure consciousness, and if so - of what sort it is".
} 
objetos puramente intencionais.

\section{Distinções ontológicas fundamentais}

Alguns dos conceitos centrais para a apreensão daquilo que Ingarden expõe em termos de uma ontologia da obra literária se encontram nas páginas do primeiro volume de Streit, dedicado a problemas ontológicoexistenciais. Especialmente, faz-se necessária uma apresentação, ainda que introdutória, dos conceitos de modos de ser (Seinsweisen) e de momentos existenciais (existentiale Momente).

Ingarden não é exatamente explícito ao 'definir' o que entende sob estes termos ${ }^{11}$. A respeito dos modos de ser, Ingarden $(2013$, p. 99) dá exemplos como ser-real (Real-Sein), ser-ideal (Ideal-Sein) e ser-possível (Möglich-Sein). Após considerar as possíveis determinações temporais ligadas aos modos de ser, Ingarden chega ao seguinte catálogo: (1) ser absoluto supratemporal; (2) ser ideal supratemporal; (3) ser real temporalmente determinado; (3) ser puramente intencional ${ }^{12}$ (INGARDEN, 2013, p. 289ss). Já os momentos existenciais são explicitados como sendo "aquilo que pode ser intuitivamente discernido e apreendido em um modo de ser por meio de abstração - por meio de uma abstração de ordem mais alta, por assim dizer"13 (INGARDEN, 2013, p. 108, tradução nossa). Ou seja, são momentos que devem pertencer a um dado modo de ser necessariamente como algo determinado pela essência (ou ideia) correspondente - ou, de acordo com Johansson (2013, p. 140), os modos de ser são complexos, e suas 'partes' constituintes são os momentos existenciais.

A elucidação do caráter preciso da suposta dependência (ou não) do mundo relativamente à consciência em jogo na querela idealismo-realismo se funda na problemática dos momentos existenciais. Ingarden identifica quatro pares de opostos destes momentos, a respeito dos quais, conforme assinala Johansson (2013, p. 141), qualquer modo de ser deverá conter um dos termos contrários dos pares ${ }^{14}$. Vejamos quais são estes momentos.

Um ente possui originalidade existencial (Seinsursprünglichkeit) se

\footnotetext{
${ }^{11}$ De acordo com Wachter (2005, p. 63), o modo como Ingarden procede em Streit não pode ser identificado com um exercício de fornecer definições formais e rigorosas. Antes, o filósofo opera por meio de exemplos, tentando apreender em certas frases aquilo que se apresenta (poder-se-ia, talvez, usar o termo 'definições' em um sentido muito frouxo).

12 Johansson (2013, p. 140) exemplifica os possíveis modos de ser da seguinte maneira, respectivamente: (1) Deus; (2) os números enquanto ideias platônicas; (3) coisas materiais; (4) entes fictícios.

13 " [...] that which can be intuitively discerned and grasped in a mode of being by means of abstraction - by means of a higher order abstraction, so to speak".

${ }^{14}$ Essa característica não se estende necessariamente ao par dependência-independência existencial, pois este é subordinado ao momento da autossuficiência. Onde esta não se encontra, tampouco a oposição anterior. Cf. INGARDEN, 2013, p. 153.
} 
não é possível, concordantemente à sua essência, que ele seja produzido (geschaffen) por outro. Se ele for produzido, então contém o momento da derivação existencial (Seinsabgeleitetheit); (INGARDEN, 2013, p. 118). Sob outro aspecto, um ente é dotado de autossuficiência (Seinsselbständigkeit) se, em decorrência de sua essência, não necessita coexistir com outro ente na unidade de um todo. Se houver tal necessidade, então se trata de um objeto determinado pelo momento da nãoautossuficiência (Seinsunselbständigkeit) (INGARDEN, 2013, p. 147). Por fim, uma vez que uma objetividade seja autossuficiente, ela pode necessitar, devido à sua essência, da existência de alguma outra entidade existencialmente autossuficiente para que possa manter sua existência continuada. Nesse caso, seu modo de ser apresenta uma dependência existencial (Seinsunabhängigkeit); se, pelo contrário, não houver tal relação, então o objeto possui independência existencial (Seinsabhängigkeit) (INGARDEN, 2013, p. 153).

O par de conceitos central na caracterização da diferença entre ser real (e também ideal) e ser meramente intencional é o que opõe autonomia existencial (Seinsautonomie) e heteronomia existencial (Seinsheteronomie). Ingarden oferece a seguinte apresentação dos conceitos:

Uma entidade (no sentido de qualquer algo em geral) existe autonomamente (é existencialmente autônomo) se possui sua fundação existencial em si mesmo. E ele a tem em si mesmo se é algo que é imanentemente determinado em si mesmo. Por outro lado, uma entidade é existencialmente heterônoma (existe heteronomamente) se possui sua fundação existencial fora de si mesma $^{15}$ (INGARDEN, 2013, p. 109-10, tradução nossa).

O que significa, nesse contexto, a imanência das determinações próprias? Ingarden dá o exemplo de uma propriedade, digamos, um momento da cor vermelha efetivamente concretizado em um dado objeto. Este possuir em si mesmo uma determinação como algo imanente é o que estabelece a autonomia existencial (assim como a qualidade ideal 'vermelho em si' também seria uma objetividade autônoma) (INGARDEN, 2013, p. 112). Ou seja, o momento 'vermelho' no objeto está efetivamente contido nele como uma determinação sua (e o mesmo vale para as demais determinações: sua forma, sua massa etc.).

Agora, a situação é diametralmente oposta quando se trata de uma objetividade heterônoma. O exemplo mais utilizado por Ingarden é o de um objeto puramente intencional. O filósofo explica que

\footnotetext{
15 "An entity (in the sense of any something at all [irgend Etwas überhaupt]) exists autonomously (is existentially autonomous) if it has its existential foundation within itself. And it has it within itself if it is something that is immanently determined within itself. On the other hand, an entity is existentially heteronomous (exists heteronomously) if it has its existential foundation outside of itself'.
} 
cada entidade puramente intencional é heterônoma, assim, uma entidade que retira seu ser e seu acervo coletivo de atributos a partir da consumação [Vollzug] de uma experiência intencional consciente, que, em uma maneira específica integrada, é dotada com um conteúdo, e ele não existiria em absoluto sem essa consumação $^{16}$ (INGARDEN, 2013, p. 113, grifo do autor, tradução nossa).

Nesse sentido, Ingarden assinala que aquilo que é adscrito pelo ato intencional da consciência é somente visado, atribuído ao correspondente objeto, mas não pode estar 'corporificado' nele como uma determinação imanente (INGARDEN, 2013, p. 115). É interessante notar que, mesmo neste texto, ao falar sobre as objetividades heterônomas (objetos puramente intencionais), Ingarden se vale de exemplos retirados da especificidade da criação artística: se, numa atitude poética, invoca-se um personagem humano, com tal e tal comportamento, com seu modo próprio de ser (real), o que se tem é o fato de que "o homem jovem e forte inventado não é 'verdadeiramente' jovem (no sentido existencialmente autônomo), não é forte, não é nenhum homem, mas, é meramente assim 'imaginado', assim 'retratado""17 (INGARDEN, 2013, p. 115, grifo do autor, tradução nossa). Dessa maneira, por contraposição, a autonomia existencial de um objeto não consiste em outra coisa senão em que as determinações que lhe cabem "são nele corporificadas, contidas nele em seu si mesmo próprio"18 (INGARDEN, 1965, p. 92, tradução nossa).

De posse destas primeiras distinções, podemos, agora, voltar-nos para aquilo que a ontologia da obra de arte literária de Ingarden tem a dizer sobre a relação entre objetos intencionais heterônomos e objetos reais autônomos.

\section{Uma ontologia da obra literária}

O primeiro ponto a ser notado em $L K$ é que a preferência de Ingarden por um tratamento ontológico do estatuto da obra literária permite uma demarcação precisa do terreno sobre o qual as análises irão se desenvolver: não se trata nem de uma psicologia da criação artística, nem de questões sobre o conhecimento da obra literária ou de sua possível valoração estética (INGARDEN, 1979, p. 3, p. 6, p. 37-8). Sob esta

\footnotetext{
16 “ $[\ldots]$ every purely intentional entity is heteronomous, hence an entity which draws its being and its collective stock of attributes from the enactment [Vollzug] of an intentional conscious experience, which in a specific integrated fashion is endowed with a content, and it would not exist at all without this enactment".

17 "The invented young, strong man is not 'actually' young (in the existentially autonomous sense), is not strong, is no man, but is merely so 'imagined', so 'portrayed".

18 "[...] sind in ihm ,,verkörpert", in ihm in ihrem eigenen Selbst enthalten”.
} 
orientação, o problema de fundo da controvérsia idealismo-realismo deve se nutrir da investigação sobre a estrutura e o modo de ser dos objetos intencionais, o que leva Ingarden a buscar dissecar uma objetividade indubitavelmente puramente intencional: a obra literária (INGARDEN, 1979, p. 4).

Seguindo esta abordagem que se orienta para o esclarecimento da "essência da obra literária" (INGARDEN, 1979, p. 37), talvez o elemento mais conhecido da teoria ingardeniana seja a ideia da multiestratificação da obra. Ingarden expõe o núcleo dessa noção da seguinte maneira:

A estrutura específica da obra literária reside, a nosso ver, no fato de ser uma produção constituída por vários estratos heterogêneos. Os estratos singulares distinguem-se entre si: primeiro, pelo respectivo material característico, de cujas particularidades resultam qualidades especiais em cada estrato; segundo, pela função que desempenha cada um deles, quer em relação aos outros estratos, quer à estruturação de toda a obra (INGARDEN, 1979, p. 45, grifo do autor).

Contudo, apesar de sua múltipla estratificação, a obra possui uma "unidade orgânica" (INGARDEN, 1979, p. 325), sobretudo quando, da polifonia harmônica entre os diferentes estratos que a compõem, alcança "seu ponto culminante na revelação das qualidades metafísicas"19 (INGARDEN, 1979, p. 321); qualidades estas que se revestem de verdadeiro valor estético e que vêm à tona no momento da concretização da obra pela leitura (INGARDEN, 1979, p. 322, p. 326). Isso remete às determinações propriamente ontológicas da obra literária, uma vez que, em última instância, ela se constituirá como um esquema a ser concretizado, mas que, contudo, não se identifica com nenhuma de suas concretizações particulares: "a obra literária é uma produção esquemática [...] é preciso apreender a obra na sua natureza esquemática e não a confundir com as concretizações singulares que surgem nas leituras individuais" (INGARDEN, 1979, p. 289). Nesse sentido, de acordo com o que destaca Mitscherling (1997, p. 139-40), embora sob uma consideração estética a obra de arte literária possa ser tomada como um todo, sob uma perspectiva ontológica (que faça abstração das qualidades estéticas), ela acaba por ser uma formação esquemática cujos elementos permanecem apenas

\footnotetext{
19 As 'qualidades metafísicas' não são qualquer propriedade objetiva das objetividades apresentadas numa obra literária. São algo que se revela em determinadas situações, como "o sublime, o trágico, o terrível, o comovente, o incompreensível, o demoníaco, o sagrado, o pecaminoso, o triste, a indescritível luminosidade da ventura [...]" (INGARDEN, 1979, p. 317). Concorrem para seu aparecimento (e, justamente, é esse aparecimento que representa o especificamente artístico da obra) todos os diferentes estratos da obra literária. Cf. INGARDEN, 1979, p. 317-26.
} 
potenciais $^{20}$.

A composição múltipla da obra se constitui de quatro estratos. $\mathrm{O}$ primeiro é o das formações fônico-linguísticas. É preciso separar, por um lado, o material fônico (sons, sinais gráficos) do sentido que se liga a ele, e, por outro, a forma significativa (a 'mesma' palavra reidentificada várias vezes) e a significação da palavra. Um material fônico só é uma forma significativa por ser portador de uma significação. A forma significativa idêntica é o que Ingarden chama de fonema significativo (Wortlaut) - é ele que é verdadeiramente o signatário de uma significação, e não o material fônico concreto. Embora não seja algo de caráter real ou ideal (como uma unidade atemporal), o fonema se apoia na realidade, estando sujeito, desse modo, à sua mutabilidade (INGARDEN, 1979, p. 51-5). A forma fonemática significativa é, de acordo com Ingarden (1979, p. 56), "'outorgada' ao material fônico concreto pela significação idêntica, chegando por esta via a manifestar-se", ou seja, o material concreto é "a base sensível para a concretização de uma e a mesma forma típica".

Apesar de se mostrar favorável à ideia de que o material fônico possa ser excluído da essência da obra, graças à distinção entre o elemento formal linguístico e o material fônico (embora, como se verá abaixo, a dimensão material/real seja um fundamento ontológico mediato para a obra), o aspecto puramente formal-significativo não pode ser deixado de lado em sua estruturação (INGARDEN, 1979, p. 71-2). Isso já nos remete para o estrato seguinte, o das unidades de significação, que se constitui como a pedra de toque da estrutura de toda a obra literária (INGARDEN, 1979 , p. 45, p. 77 , p. 208, p. 211). Este segundo estrato está intimamente ligado àquele das formações linguísticas, pois

pertence à ideia de significação estar ligada a qualquer forma significativa (ou a qualquer sinal verbal de natureza visual, acústica, táctil) e ser por isso a sua significação. Encontra nessa forma o seu invólucro externo, a sua "expressão", o seu portador exterior. Sem uma "forma significativa" (no sentido, agora ampliado, de um fator formal qualitativo de qualquer gênero) a significação não poderia de modo algum existir (INGARDEN, 1979, p. 77, grifo do autor).

O estrato das significações será o ponto do qual irá irradiar a realidade projetada pela obra, isto é, aquilo que Ingarden irá chamar em seu

\footnotetext{
${ }^{20}$ É preciso reconhecer, aqui, conforme assinala Limido-Heulot (2011), a tensão que esse tipo de caracterização traz à abordagem ingardeniana. Pois se trata, de uma parte, de circunscrever rigorosamente o campo de investigações à dimensão ontológica da obra, por exclusão das qualidades estéticas. Entretanto, o aparecimento das qualidades metafísicas remete à concretização pelos atos do leitor. Parece, aqui, revelar-se uma passagem sutil do âmbito de uma ontologia para uma fenomenologia da obra literária, pois se trata da constituição de valores estéticos que não estão dados a priori.
} 
conjunto de "objetividades apresentadas" (INGARDEN, 1979, p. 239) - os objetos puramente intencionais em seu 'mundo' próprio. Procuremos entender melhor como isso ocorre.

Uma significação é "tudo quanto está ligado à forma significativa verbal e constitui com ela uma "palavra" (INGARDEN, 1979, p. 82). As significações são algo atribuído ao fonema por um ato subjetivo, o que determina que, por meio de seu significado, uma palavra se dirija intencionalmente a um objeto. Com efeito, Ingarden explica que

a referência intencional contida na significação é, por assim dizer, o reflexo do pensar intencional contido no ato doador de significação A intencionalidade da palavra é uma intencionalidade emprestada pelo ato correspondente [...] Aqui, o ato de consciência cria propriamente algo que anteriormente não existia, embora nada consiga criar que uma vez criado possa existir com autonomia no seu próprio $\operatorname{ser}^{21}$. O criado neste caso em comparação com o ser real, o ser ideal e finalmente o da pura consciência é apenas algo análogo à "aparência", algo que apenas pretende ser alguma coisa sem todavia o ser no sentido da autonomia real (INGARDEN, 1979, p. 121, grifo do autor).

Os elementos significativos que aparecem numa obra não são, contudo, palavras isoladas, mas frases (INGARDEN, 1979, p. 111), que, por sua vez, também resultam de operações intencionais subjetivas que Ingarden chama de "operações individuais produtoras de frases" (1979, p. 125). Aqui, é importante compreender a discussão de Ingarden sobre o estado atual e potencial da significação de uma palavra. Uma palavra expressa, isto é, atualiza um conteúdo de sentido pertencente a um conceito ideal correspondente a determinada objetividade. No entanto, permanece um conteúdo não expresso, somente potencial da significação (e que pode, portanto, vir a ser atualizado) (INGARDEN, 1979, p. 107-8). As significações de expressões isoladas se unem para formar uma nova unidade de sentido - a frase (INGARDEN, 1979, p. 112) - a partir das operações subjetivas que atualizam parte do conteúdo ideal de significação de um conceito (INGARDEN, 1979, p. 396).

Como consequência, as frases assim construídas projetam um correlato, um objeto puramente intencional - o correlato de uma frase é o que Ingarden chama de relação objetiva (Sachverhalt), que deve ser distinguida de um estado-de-coisas realmente existente (INGARDEN, 1979, p. 134-7). Por meio destas projeções, o estrato das significações desempenha sua função, que é a de apresentar, dar a conhecer as

\footnotetext{
${ }^{21}$ Ou seja, uma palavra, enquanto forma significativa portadora de uma significação que lhe é outorgada pela consciência, é ontológico-existencialmente derivada e heterônoma em seu ser.
} 
objetividades contidas na obra através do desenvolvimento das relações objetivas puramente intencionais (INGARDEN, 1979, p. 214), dado que no desenvolvimento de relações objetivas a partir de frases 'abre-se' o objeto, penetra-se intencionalmente em seu 'interior' (INGARDEN, 1979, p. 1556). Nesse sentido, as conexões de frases referidas a um mesmo objeto portanto, que o apresentam sob diferentes relações objetivas - formam uma espécie de 'rede' na qual ele é 'apanhado' (INGARDEN, 1979, p. 178-9). Assim, a função maior do estrato das unidades de significação é a apresentação das objetividades da obra, sendo responsável, portanto, pela constituição de seu estrato objetivo (INGARDEN, 1979, p. 208-9), o qual apresenta uma 'realidade' própria, um “mundo à parte" em que é instituída uma "ilusão de seriedade" (INGARDEN, 1979, p. 190).

Os dois estratos restantes, a saber, o das objetividades apresentadas e o dos aspectos esquematizados, encontram-se em estreita conexão. Apenas algumas breves explicações serão suficientes a seu respeito, dado que se voltará a falar dos correlatos intencionais projetados pelas unidades de significação na seção seguinte de nosso trabalho.

Os objetos apresentados numa obra literária são determinados pelo conteúdo de sentido das frases, portanto, por meio da projeção de uma série de relações ontológicas que se desenvolvem numa esfera de ser (INGARDEN, 1979, p. 240) - pense-se, por exemplo, em Hamlet, que é concebido como um homem real, vivendo em um mundo também real e mergulhado em situações que se desenrolam nessa esfera de ser. É projetado um "setor de um mundo" (INGARDEN, 1979, p. 240), que funciona como um pano de fundo, geralmente não definido em seus detalhes, dado que é projetado não somente pelo estado atual das significações, mas, geralmente, mais pelo seu estado potencial (INGARDEN, 1979, p. 241). Obviamente, há nesta realidade uma modificação de seu caráter que a reduz à mera "pretensão de realidade" (INGARDEN, 1979, p. 243) - todos os modos de ser apresentados passam por esta mudança, o que os coloca sob a chancela do 'quase' - 'como se' fosse real, uma 'quasi-realidade' (INGARDEN, 1979, p. 244).

Por fim, os aspectos (Ansicht) esquematizados podem ser compreendidos por analogia com o modo segundo o qual os objetos reais se dão a um sujeito: há uma diferença entre o objeto e os aspectos nos quais ela aparece (INGARDEN, 1979, p. 280-1). Todo aspecto percebido remete para uma infinidade de outros possíveis, os quais compõem "um esqueleto, um esquema dos aspectos concretos em devir", ou seja, há certa idealização da totalidade de aspectos correlacionados à coisa que se dá (INGARDEN, 1979, p. 286, grifo do autor). Na obra literária, por sua vez, há uma projeção de aspectos esquematizados graças ao sentido potencial contido nas relações objetivas constituídas como correlatos das frases; estas estabelecem prédeterminações para a atualização de vários aspectos quando das concretizações particulares no momento da leitura (INGARDEN, 1979, p. 
288). Nesse sentido, é importante destacar que os objetos projetados na obra serão portadores do que Ingarden chama de "pontos de indeterminação" (1979, p. 292), pois os aspectos pré-estabelecidos só podem ser aqueles ligados ao que explicitamente é apresentado das objetividades. Além disso, os aspectos permitem certa apreensão 'intuitiva' destas objetividades, as quais, de outro modo, permaneceriam como simples esquemas conceituais vazios (INGARDEN, 1979, p. 301-2). Desse modo, torna-se mais fácil compreender algo que já havia sido apontado acima, a saber, que a obra literária consiste de uma formação esquemática, potencial.

É, portanto, essa intrincada estrutura multiestratificada que compõe um todo polifônico e harmônico que permite a Ingarden estabelecer o estatuto ontológico da obra de arte literária como uma objetividade puramente intencional, composta das objetividades (apresentadas por meio de relações objetivas) 'criadas' pelo conteúdo de sentido das frases e de sua concatenação em unidades mais amplas.

Procuremos ver, agora, em que esta ontologia da obra literária pode contribuir no debate ingardeniano com seu mestre de outrora.

\section{A tripla fundação ontológico-existencial da obra literária}

Quase no momento em que as cortinas caem para A obra de arte literária, Ingarden se vê diante da dificuldade de justificar a possibilidade de que a obra literária (com a totalidade de suas frases) mantenha sua existência mesmo depois de criada pelo autor, ao mesmo tempo em que não se dilua em uma profusão de concretizações particulares (pelos atos intencionais dos leitores). Por outro lado, ela também não pode ser identificada a uma objetividade ideal autônoma, pois isso tornaria ininteligível sua reprodução em exemplares reais múltiplos, seu vir-a-ser em algum momento do tempo, bem como qualquer alteração que pudesse vir a sofrer $^{22}$. É nesse ponto que intervém a natureza existencialmente heterônoma da obra enquanto objetividade puramente intencional, que resultará numa tripla fundação ontológica.

Em relação ao fundamento ôntico das frases, uma vez criadas, deve-

\footnotetext{
${ }^{22}$ Este é um problema de fundo de todas as discussões de $L K$, pois diz respeito ao modo de ser da obra literária. Ingarden apresenta a dificuldade nos §§ 3-6. A questão é determinar se uma obra literária configura um objeto real ou ideal. Ambas as alternativas parecem insuficientes, o que leva Ingarden a elaborar sua teoria sobre o estatuto puramente intencional da obra. Com efeito, se esta for algo de real (material ou psíquico), como justificar sua identidade como uma mesma obra? Por outro lado, se ela for algo de ideal (portanto, um objeto atemporal, não passível de criação e alterações), como justificar o fato inegável de que as obras literárias são criadas por seus autores e, por vezes, até mesmo modificadas ao longo do tempo? Aqui, quase ao final de seu livro, Ingarden chega a uma solução para o problema, fazendo do aspecto concreto/material e dos conceitos ideais fundamentos ontológicos para o subsistir da obra e para sua heteronomia existencial, mas, sem transformá-los em estratos efetivamente constituintes seus.
} 
se lembrar o que foi dito a seu respeito enquanto atualizações de parte do sentido contido num conceito ideal. Nas operações construtoras das frases, constitui-se algo novo, a saber, o conteúdo de sentido (de uma frase ou conexão de várias delas). Os conceitos, por sua vez, não fazem realmente parte da obra, mas funcionam como "o fundamento ontológico das frases e o princípio regulador da sua construção" (INGARDEN, 1979, p. 396). Isso significa que as frases possuem duas fundações ontológicas: pelo lado de seu vir-a-ser, os atos criadores da consciência; pelo lado de seu subsistir no ser, os conceitos ideias dos quais são somente atualizações parciais (INGARDEN, 1979, p. 397). Ora, estes dois elementos são transcendentes relativamente às frases e à obra como um todo. Tem-se, aqui, a razão da heteronomia da obra literária enquanto objeto puramente intencional:

A objetividade que existe de um modo ontologicamente heterônomo não tem - dissemos - nenhum fundamento ontológico em si própria, mas remete para um ser diferente e decerto, em última análise, para um ser ontologicamente autônomo. $\mathrm{O}$ ato intencional da consciência pura não é criador no sentido de criar realizações autênticas de essencialidades ideais ou de conceitos ideais num objeto por ele intencionalmente produzido. Se ele fosse criador nesse sentido, então seria capaz de criar objetividades autênticas reais e, eo ipso, ontologicamente autônomas. Isto, porém, é-lhe vedado. Assim, no caso da construção de uma frase ele pode produzir atualizações de conteúdos ideais de sentido dos conceitos e inseri-las numa nova totalidade (justamente o conteúdo de sentido da frase) e precisamente atualizações a que nenhum conteúdo ideal de sentido, na forma ontológica das realizações, é realmente inerente ou, na verdadeira acepção do termo, imanente, como sucede nas realizações de essencialidades ideais em objetos reais (e, ipso facto, autônomos no seu ser). E do mesmo modo: se através do ato de consciência é criado um objeto puramente intencional (p. ex., uma "coisa"), a intenção nele contida não tem a capacidade de produzir nenhuma autêntica realização de qualquer essencialidade ideal. A coisa intencionalmente criada não "é" - em sentido rigoroso ontologicamente autônomo - p. ex., "vermelha". Para que o pudesse ser teria de conter em si realmente uma realização autêntica da essencialidade "vermelho" (INGARDEN, 1979, p. 397-8, grifo do autor).

Ou seja, seguindo as definições apresentadas em Streit $^{23}$, nem os atos criadores do autor podem realizar momentos efetivamente ideais do conteúdo ideal de significação nas frases, nem as unidades de sentido podem projetar realizações efetivas das determinações próprias às objetividades intencionais apresentadas, isto é, tanto no conteúdo de sentido das frases, quanto naquele das objetividades 'criadas', falta a imanência das

${ }^{23}$ Cf. acima, seção 3. 
determinações próprias. A situação fica mais clara com o que Ingarden explicita em seguida:

\begin{abstract}
Quem admitir a existência ontologicamente heterônoma das frases tem também de aceitar todos os seus fundamentos ontologicamente autônomos e não se pode limitar à aceitação dos atos puros da consciência. Pois assim como uma frase não poderia surgir sem uma operação construtora de frases, também não poderia existir de modo ontologicamente heterônomo sem os conceitos ideais. Isto é exigido precisamente pela heteronomia ontológica que lhe é própria, por um lado, e pela circunstância de que ela é uma formação de sentido, por outro (INGARDEN, 1979, p. 398, grifo do autor).
\end{abstract}

Mas, além do problema da fundação ontológica e da manutenção da identidade intersubjetiva das frases (a partir dos conceitos ideais intersubjetivos), há ainda a questão da identidade do estrato fônicolinguístico, já que este opera como um suporte exterior para as significações. Juntamente com a obra, este estrato deve se manter o mesmo (INGARDEN, 1979, p. 401).

Ingarden explica que o autor já parte de uma "língua viva", na qual se encontram de antemão uma infinidade de fonemas significativos. Há, portanto, certa forma fixa para estes, pois embora não sejam objetividades ideais autônomas, "são indubitavelmente formados durante o processo de evolução de uma língua e tornam-se depois relativamente fixos" (INGARDEN, 1979, p. 400). Agora, o ponto chave será a efetivação destas formas fônicas num substrato material real, qual seja, o "material individualizado [...] visualmente apreensível" no qual devem ser gravados os sinais gráficos correspondentes aos fonemas significativos ${ }^{24}$ (INGARDEN, 1979, p. 402). Nesse contexto, o problema se ramifica em duas questões: (1) "O que é que acontece com o fundamento ôntico da identidade de fonemas significativos e com a sua legitimação nas concretizações particulares da obra?” (INGARDEN, 1979, p. 401); e (2) "Como é que os fonemas significativos [...] se podem justificar como intersubjetivamente idênticos quando são lidos por diferentes sujeitos?" (INGARDEN, 1979, p. 402). Ambas as questões nos direcionam para a concretização dos fonemas significativos.

Em relação à primeira pergunta, Ingarden (1979, p. 401) afirma que a existência continuada do estrato linguístico como sendo o mesmo "é possível pelo fato de haver ideias para todos os seres objetivos". Por sua vez, os fonemas efetivamente pronunciados (ou escritos) funcionam como

\footnotetext{
${ }^{24}$ Obviamente, considerando a ressalva assinalada pelo próprio Ingarden: "Desde que não deva ser transmitida apenas 'oralmente', e para que nesta transmissão puramente oral não sofra alterações de monta, a obra literária tem que ser escrita" (INGARDEN, 1979, p. 402, grifo do autor).
} 
concreções autênticas das formas fônicas típicas, ou seja, são seres objetivos. Assim, segundo Ingarden,

\begin{abstract}
a intenção que torna os fonemas significativos, no sentido de formas típicas, partes integrantes da obra literária, produz simultaneamente uma concretização intencional dos conteúdos das correspondentes ideias presentes nos fonemas significativos concretamente pronunciados; esta concretização é diferente das ideias em si mesmas e só ontologicamente heterônoma, mas tem nessas ideias o seu fundamento ôntico, o que justifica onticamente perante todas as suas concretizações a identidade dos fonemas significativos que pertencem à obra em questão (INGARDEN, 1979, p. 401-2).
\end{abstract}

Desse modo, por meio de um desvio pela concretização material da forma significativa, assegura-se a identidade do estrato fônico-linguístico, que, mesmo sendo puramente intencional, subsiste no ser, devido à fundação numa objetividade ideal (contraparte da instanciação desta num objeto real), como o mesmo conjunto de formas significativas típicas escolhidas pelo autor da obra para compô-la.

A segunda questão conduz ao fato de que, partindo de um contexto linguístico no qual certas formas são intersubjetivamente idênticas, faz-se necessário "um sinal que indique aos leitores que precisamente no caso dado se trata dessas e não de quaisquer outras palavras" (INGARDEN, 1979, p. 402). Ou seja, esses 'sinais' nada mais são que o conjunto de caracteres gráficos engastados num suporte material: de acordo com Ingarden, "os 'caracteres gráficos', com sinais de emprego de fonemas significativos correspondentes, têm que ser fixados num material real estável e relativamente pouco mutável" (INGARDEN, 1979, p. 402, grifo do autor). O resultado disso é que, não obstante Ingarden não aceitar o material gráfico real e os caracteres impressos como elementos essenciais da obra, eles acabam por constituir "um fundamento ôntico mediato da obra que possibilita a apreensão das formações fônico-linguísticas idênticas" (INGARDEN, 1979, p. 403, grifo do autor). Ou seja, o substrato material surge como um fundamento mediato da subsistência das formações fônicolinguísticas escolhidas pelo autor no momento de criação da obra como aquelas que devem veicular as atualizações de significações extraídas dos conceitos ideais.

A constatação desta situação leva Ingarden a assumir que "este material real a que se deu forma adequada constitui, ao lado das operações subjetivas, dos conceitos ideais, das essencialidades e das ideias, o terceiro, ainda que mediato, fundamento ôntico da obra literária" (INGARDEN, 1979, p. 402). Nesse sentido, Mitscherling (1997, p. 154) explicita que o que se tem é uma tripla base ôntica da obra: (1) as operações subjetivas; (2) os conceitos ideais intersubjetivos; e (3) o material gráfico real. Ou seja, a obra literária, na sua condição ontológica heterônoma de objeto puramente 
intencional, necessita de duas bases ontológicas, além da projeção intencional dos atos da consciência, para que possa subsistir em seu ser e extrair destas objetividades que lhe são heterogêneas o conjunto de determinações próprias que lhe cabem.

O que importa é perceber que, desse modo, alcança-se um dos elementos chave para a réplica realista de Ingarden a Husserl. Ao menos uma das teses centrais do idealismo transcendental seria diretamente confrontada, a saber, a afirmação de que o objeto intencional encontra seu fundamento único na consciência. Se mantivermos em mente as distinções ontológicas elaboradas em Streit a respeito dos diferentes sentidos em que um ente pode ser existencialmente dependente de outro e considerarmos os resultados de $L K$, em que se demonstra que a obra de arte literária - um objeto puramente intencional - não pode ter somente os atos intencionais como fundação ontológica (pois necessita, no sentido da heteronomia e da dependência existencial, das objetividades ideais e reais), torna-se possível vislumbrar como Ingarden dá um passo na direção de pôr em xeque aquele pilar do idealismo husserliano. No entanto, também se percebe que o alcance de suas análises é ainda maior. De acordo com Mitscherling (1997, p. 154), a interpretação ingardeniana do idealismo de Husserl assinala que este faria dos atos da consciência o fundamento ontológico das objetividades ideais e reais. Entretanto, as investigações sobre a obra literária levaram à conclusão de que estas objetividades é que são necessárias para a possibilidade dos objetos puramente intencionais. Ainda conforme explica Mitscherling (1997, p. 154), a resposta realista de Ingarden é mais visível em relação aos objetos reais, mas sua postura mais incisiva recai sobre a afirmação da autonomia existencial das objetividades ideais: "Com efeito, sem as essencialidades ideais e as ideias as objetividades puramente intencionais são impossíveis" (INGARDEN, 1979, p. 399).

Obviamente, ao desafiar a ideia segundo a qual os únicos fundamentos ontológicos dos objetos intencionais se devem à consciência, Ingarden põe em dificuldades também a negação husserliana de um objeto transcendente 'em si', bem como a afirmação de que todos os objetos se reduzem a correlatos intencionais (noções que, ao fim, estão entrelaçadas entre si e com a que viemos discutindo). Mas, os elementos que se mostram mais pertinentes para a discussão destas teses husserlianas se encontram nas explanações de Ingarden acerca da estrutura das objetividades puramente intencionais. É a estas que voltaremos, agora, nossa atenção.

\section{Objetos reais e objetos intencionais}

No prefácio à primeira edição de $L K$, Ingarden assinala três elementos resultantes de sua investigação que se opõem diametralmente ao idealismo de Husserl: a estrutura dupla das objetividades puramente 
intencionais, os pontos de indeterminação relativos ao seu conteúdo e sua heteronomia ontológica (INGARDEN, 1979, p. 6). Este último ponto foi explorado na seção anterior de nosso trabalho, destacando as diferentes objetividades que determinam essa heteronomia e a impossibilidade de reduzi-las apenas às operações subjetivas. Interessa-nos, agora, inquirir os dois outros aspectos indicados pelo filósofo polonês. Comecemos por algumas características relacionadas aos objetos puramente intencionais, a fim de compreender como elas acarretam a inviabilidade da identificação, pretendida por Husserl, entre objetos reais e intencionais. De início, é interessante enfatizar que Ingarden indica repetidamente que as distinções relativas a estas objetividades são resultados ontológicos, isto é, derivados segundo a ideia (essência) destas objetividades (INGARDEN, 1979, p. 138, p. 140, p. 269).

Comecemos com a definição oferecida por Ingarden para os objetos puramente intencionais:

Entendemos por objetividade puramente intencional uma objetividade "criada" em sentido figurado por um ato de consciência ou uma multiplicidade de atos ou, em última análise, por uma formação linguística (p. ex., a significação da palavra, a frase) portadora da intencionalidade outorgada exclusivamente em virtude da intencionalidade a eles imanente, original ou apenas outorgada, tendo essa objetividade a origem do seu ser e de todo o seu modo de ser nestas objetividades mencionadas $^{25}$ (INGARDEN, 1979, p. 137-8, grifo do autor).

Essa primeira delimitação já nos coloca em posição para apreender duas distinções relevantes: a primeira, entre objetos puramente intencionais e os "também intencionais", isto é, aqueles autônomos em seu ser, mas que podem, eventualmente, ser alvo de uma visada intencional (INGARDEN, 1979 , p. 138) ${ }^{26}$; a segunda, entre objetos pura/originariamente intencionais (têm a origem de seu ser e modo de ser diretamente nos atos da consciência) e os pura/derivadamente intencionais (cuja origem e determinação ontológica se assenta sobre as unidades de significação que, como vimos, recebem sua intencionalidade graças aos atos de consciência) (INGARDEN, 1979, p. 138). Este último tipo de objetividade intencional, portanto, apresenta certa mediatez em sua fundação ontológico-existencial ${ }^{27}$. Com

${ }^{25}$ Logo, estipula-se, de saída, que os objetos puramente intencionais são existencialmente derivados e heterônomos.

${ }^{26} \mathrm{O}$ mesmo no primeiro volume de Streit. Cf. INGARDEN, 2013, p. 113-4.

27 Não se deve confundir a diferenciação aqui em jogo com aquela existente entre derivação e originalidade existenciais (cf. acima, seção 3). A distinção, aqui, remete ao fato de que nem todo objeto intencional possui em sua fundação existencial imediata sua fundação última. Pode ocorrer (como no caso das objetividades intencionais puras e derivadas) que a fundação existencial imediata seja, também ela, uma objetividade heterônoma. Esta, por sua vez, deve remeter a uma fundação última numa objetividade 
efeito, as objetividades apresentadas numa obra literária são pura e derivadamente intencionais, pois têm como fundação existencial imediata as unidades de significação (especialmente as frases) (INGARDEN, 1979, p. 239).

Os objetos intencionais são ainda transcendentes relativamente aos atos em que são projetados, pois não se encontram como seus momentos reais (reellen), consistindo, assim, somente de correlatos dos atos subjetivos nos quais possuem sua origem (INGARDEN, 1979, p. 139) ${ }^{28}$.

Agora, ao se deter em certos detalhes formais relativos às objetividades puramente intencionais, Ingarden encontra elementos que viabilizam a negação da identificação husserliana entre estas e os objetos reais. Especificamente, trata-se da duplicidade ou bilateralidade (Doppelseitigkeit) formalmente essencial aos objetos intencionais ${ }^{29}$. Em todo objeto intencional, explica Ingarden (1979, p. 139), temos, por um lado, seu conteúdo, e, por outro, sua estrutura enquanto objeto intencional. Numa objetividade meramente 'representada' (por exemplo, uma mesa), tem-se, em seu conteúdo, três elementos: (1) sua estrutura formal enquanto 'coisa'; (2) suas determinações materiais (qualitativas) que a estabelecem com uma 'mesa'; (3) o modo de ser real (intencionado) da mesa (INGARDEN, 1979, p. 139). No conteúdo, relativamente ao primeiro momento assinalado, encontra-se o caráter formal de ser um portador de qualidades reais (portador este qualitativamente delimitado como, especificamente, uma 'mesa') (INGARDEN, 1979, p. 139-40). Ou seja, enquanto 'mesa' (como conteúdo do objeto puramente intencional), ela possui uma determinada massa, certo tamanho, um momento sensível que a determina como possuindo uma 'cor' etc. Mas, o que precisa ser notado é que nada disso diz respeito ao portador especificamente de um objeto enquanto puramente intencional, pois aquele primeiro portador é relativo somente ao seu conteúdo. O objeto intencional possui um portador próprio, ao qual se encontram ligadas qualidades distintas daquelas referidas ao portador delimitado pelo seu conteúdo, como, por exemplo, a característica

autônoma. É o que ocorre com as objetividades apresentadas numa obra literária: sua fundação existencial imediata se constitui das frases que as projetam intencionalmente; estas, por sua vez, são também heterônomas, encontrando sua radicação ontológicoexistencial última nas operações subjetivas construtoras de frases. Cf. INGARDEN, 1979, p. 138-9; 2013, p. 117.

${ }^{28} \mathrm{Ou}$ seja, enquanto transcendentes à consciência nesse sentido, os objetos intencionais são existencialmente autossuficientes, pois não necessitam formar a unidade de um todo com o ato para seu modo de ser. Entretanto, conforme se viu nas discussões anteriores, ele são existencialmente dependentes, pois necessitam de outra objetividade também autossuficiente para sua subsistência no ser.

${ }^{29}$ Esta característica do objeto puramente intencional é examinada em detalhe na primeira parte do segundo volume de Streit, § 47. Aqui, limitamo-nos, conforme já estabelecido ao início do texto, a apontar aquilo que Ingarden expõe em $L K$. Uma análise detalhada das investigações ontológico-formais de Streit estaria, nesse momento, muito além daquilo a que nos propusemos neste trabalho. 
de ser somente algo de visado, que 'pertence' a um ato de consciência, que possui um conteúdo etc. (INGARDEN, 1979, p. 140). Desse modo, somos levados à conclusão de que

\begin{abstract}
há, por conseguinte, uma duplicidade curiosa de aspectos e de "suportes" na estruturação do objeto puramente intencional, constituindo por si mesma uma particularidade formal característica do objeto puramente intencional (não pertencendo, portanto, ao seu conteúdo), particularidade essa que nos objetos individuais e autônomos no seu ser relativamente aos atos da consciência não só é inexistente mas, por essência, excluída [...] Se ter um conteúdo é uma qualidade do objeto puramente intencional, o "portador da mesa" pertence ao âmbito do possuído pelo objeto e não exerce nele qualquer função de portador. Exerce-a apenas em relação aos outros momentos de conteúdo (as qualidades da "mesa" intencionada) e só o "faz" num sentido muito modificado [...] p. ex., para se distinguir da função de portador de um objeto autônomo no seu ser (INGARDEN, 1979, p. 140-1, itálico do autor, negrito nosso).
\end{abstract}

Ou seja, o que a análise da estrutura formal de um objeto puramente intencional revela é que ele possui uma duplicidade impossível a priori para as objetividades reais, pois estas são portadoras de suas qualidades de maneira 'única'; não lhes é possível desfrutar da característica formal de serem duplamente portadoras de determinações. Ingarden ainda alerta que, se não se admite a distinção entre estrutura intencional e conteúdo, teríamos então de aceitar momentos contraditórios nos correlatos das frases, pois a todo objeto intencional 'projetado' pertence essencialmente o modo de ser heterônomo; mas, naquilo que se apresenta em seu conteúdo, podemos ter modos de ser autônomos, como o real ("Friburgo está situado em Baden") ou o ideal ("As diagonais do quadrado cruzam-se em ângulo reto") (INGARDEN, 1979, p. 152).

Mas, há ainda uma segunda característica essencial pertencente às objetividades apresentadas na obra literária que as torna radicalmente diferentes dos objetos reais. Ela se conecta com o fato, aludido anteriormente, de que grande parte daquilo que é projetado pela obra assim se dê graças ao conteúdo potencial das frases, não sendo, portanto, definitivamente determinado, permanecendo sob certa forma esquemática. Ingarden aprofunda este tema ao tratar dos 'pontos de indeterminação' das objetividades apresentadas. Estas são projetadas como algo de real pelo seu conteúdo, sendo que às objetividades reais pertencem, por essência, as características de serem unívoca e completamente determinadas numa unidade concreta original, individual (INGARDEN, 1979, p. 269-70). Isso quer dizer, então, que um objeto real "no seu modo de ser não assinala qualquer ponto de indeterminação" (INGARDEN, 1979, p. 269, grifo do 
autor). Ora, os objetos intencionais são projetados por uma quantidade finita de unidades de significação, que explicitam somente uma parcela das determinações pertencentes aos objetos (que são, pelo sentido que lhes é próprio, representados como uma unidade concreta portadora de infinitas determinações) (INGARDEN, 1979, p. 269, p. 271-2). Resta, desse modo, uma gama infindável de pontos de indeterminação somente covisados graças à potencialidade das unidades de significação.

Portanto, nem o objeto apresentado é total e univocamente determinado no seu conteúdo, nem é infinita a quantidade das determinações univocamente definidas e positivamente atribuídas, nem ainda a das simplesmente coapresentadas: só é projetado um esquema formal de uma quantidade infinita de pontos de determinação que ficam quase todos por preencher (INGARDEN, 1979, p. 273, grifo do autor).

Ao analisar este tema, Mitscherling (1997, p. 108) assinala que, por exemplo, Tolstoi poderia ter dedicado um capítulo inteiro somente para descrever minuciosamente a aparência física de Anna Karenina. Entretanto, a descrição jamais poderia vir a ser exaustiva. $E$ isso por uma dupla via (que nos parece interligada): por um lado, a complexidade da objetividade a ser descrita - pense-se no exato enrolar dos cachos dos cabelos que Anna estaria constantemente escovando -, por outro, o caráter finito do conteúdo de um ato intencional - e isso em relação tanto ao leitor, no momento da concretização da obra na leitura, quanto ao autor, quando de sua criação. Assim, os pontos de indeterminação constantes na obra literária - que representam uma propriedade essencial de qualquer objeto puramente intencional - trazem à cena mais uma característica que diferencia irremediavelmente este tipo de objetividade dos objetos reais. Ou, dito de outro modo, qualquer objeto ontológico-existencialmente determinado conforme ao modo de ser intencional (heterônomo) não pode, sob pena de transgredir uma legalidade formal apriorística, ser amalgamado com uma objetividade cujo modo de ser seja o real.

Com estes resultados, Ingarden assinala o caminho para aquilo que anunciara já no prefácio de $L K$, a saber, examinar a estrutura de um objeto puramente intencional e determinar se uma objetividade real poderia compartilhá-la (INGARDEN, 1979, p. 4). Por isso Ingarden afirma, já ao início de Streit, que os esforços de $L K$ representavam um primeiro passo na delimitação mútua entre entes reais e intencionais, baseando-se, para isso, num estudo sobre as diferentes formas destes tipos de objetividades; o que, por fim, mostraria que a pretensão idealista de reduzir os objetos reais aos intencionais se configura como uma impossibilidade (INGARDEN, 2013, p. 20).

\section{Conclusão}


As investigações sobre o estatuto ontológico da obra literária permitem a Ingarden encontrar distinções importantes para a delimitação de sua postura crítica no que concerne ao idealismo husserliano. A compreensão da obra como um objeto puramente intencional, bem como as análises formais a respeito das objetividades nela apresentadas, surgem como alicerce para a resposta realista de Ingarden, uma vez que o filósofo polonês acredita ter apresentado, com sucesso, a ideia de que o mundo real não poderia ser reduzido a mero correlato de atos intencionais; consequentemente, também se deveria admitir a existência de objetividades autônomas reais e ideais que desfrutam de um modo de ser independente da consciência.

À luz do que foi exposto, podemos agora caracterizar a obra literária, enquanto objetividade puramente intencional, segundo os termos exatos da ontologia ingardeniana: trata-se de um objeto existencialmente derivado (criado pelos atos intencionais do autor), heterônomo (retira destes mesmos atos e do conteúdo de sentido das frases suas determinações), autossuficiente (não é um momento real [reell] do ato intencional, mas lhe é transcendente, não constituindo, com ele, a unidade de um todo) e dependente (necessita a existência de outras objetividades para sua existência continuada: os conceitos ideais e o substrato material real). Relativamente à controvérsia idealismo-realismo, o que se deve notar é que esta delimitação do sentido em que um objeto intencional é existencialmente dependente (em especial, seu caráter heterônomo) abre caminho para uma crítica impetuosa da tese husserliana de que estas objetividades teriam seu único fundamento ontológico-existencial na consciência pura. Conforme visto, a obra literária requer, enquanto objetividade puramente intencional, outros fundamentos ônticos que justifiquem seu modo de ser: os conceitos ideais e o substrato material gráfico que determinam sua heteronomia (esta, em parte) e sua dependência existencial. Além disso, as investigações sobre os aspectos ontológico-formais dos objetos intencionais e sua contraposição àqueles essenciais aos objetos reais coloca em dificuldades outra tese central do idealismo transcendental de Husserl, a saber, a redução de todo objeto do mundo real a mero correlato dos atos da consciência e a consequente negação de um objeto transcendente 'em si'.

Como nota final, pensa-se que talvez a grande questão que teria de ser considerada em toda sua amplitude é a de se seria possível aceitar, desde a perspectiva filosófica de Husserl, o ponto de partida escolhido por Ingarden. Afinal, como o próprio Husserl assinala em uma carta de 1931 destinada a Ingarden ${ }^{30}$, uma vez que se compreenda o verdadeiro sentido de sua fenomenologia constitutiva, já não seria possível perseguir uma ontologia da maneira pressuposta pelas críticas de Ingarden. Obviamente,

${ }^{30}$ Cf. HUSSERL, 1968, p. 73. 
explorar o sentido e os desdobramentos implicados nesta observação de Husserl não poderia ser nosso objetivo aqui. Entretanto, a crítica ingardeniana ao idealismo transcendental-fenomenológico, edificada sobre uma estruturação ontológica intrincada e robusta, para além de seu evidente valor filosófico intrínseco, mostra claramente ser digna de atenção por parte daqueles interessados no estatuto da fenomenologia husserliana. Trata-se de considerações críticas desenvolvidas sob o escrutínio do mais honesto espírito de uma 'filosofia enquanto ciência de rigor', tal como preconizava o famoso imperativo husserliano; reflexões que claramente não podem ser descartadas com um simples dar de ombros. Aqui, talvez, caiba relembrar e fazer valer o alerta hegeliano em sua introdução à Fenomenologia do espírito: "Um asseverar seco vale tanto como qualquer outro" (HEGEL, 2011, p. 74). 


\section{Referências bibliográficas}

HEGEL, G. W. F. Fenomenologia do espírito. $6^{\mathrm{a}}$ ed. Tradução de Paulo Meneses. Petrópolis, RJ: Vozes, 2011.

HUSSERL, E. Briefe an Roman Ingarden. Den Haag: Martinus Nijhoff, 1968.

Formal and Transcendental Logic. Translated by D. Cairns. The Hague: Martinus Nijhoff, 1969.

Ideias para uma fenomenologia pura e para uma filosofia fenomenológica. Tradução de M. Suzuki. Aparecida, SP: Ideias \& Letras, 2006. 70, 2008.

A ideia da fenomenologia. Tradução de A. Morão. Lisboa: Edições Meditações cartesianas e conferências de Paris. Tradução de P. M. S. Alves. Lisboa: Centro de Filosofia da Universidade de Lisboa, 2010.

INGARDEN, R. Der Streit um die Existenz der Welt. Band 2: Formalontologie. Teil 1. Tübingen: Max Niemeyer Verlag, 1965.

On the Motives which led Husserl to Transcendental Idealism.

Translated by A. Hannibalsson. Den Haag: Martinus Nijhoff, 1975.

The Letter to Husserl About the VI [Logical] Investigation and

'Idealism'. In: TYMIENIECKA, A.-T. (Ed.). Ingardeniana: A Spectrum of Specialised Studies Establishing the Field of Research. Dordrecht, Boston: D. Riedel Publishing Company, 1976, p. 419-38. (Analecta Husserliana). A obra de arte literária. $2^{a}$ ed. Tradução de A. E. Beau, M. C. Puga e J. F. Barrento. Lisboa: Fundação Calouste Gulbenkian, 1979.

. Controversy over the Existence of the World. Volume I. Translated and annotated by A. Szylewicz. Frankfurt am Main: Peter Lang Edition, 2013.

JOHANSSON, I. Proof of the Existence of Universals - and Roman Ingarden's Ontology. Metaphysica, vol. 10, n. 1, p. 65-87, 2009.

2013 . The Basic Distinctions in Der Streit. Semiotica, vol. 194, p. 137-57,

LIMIDO-HEULET, P. Sens et limites de l'analyse ontologique dans l'esthétique de Roman Ingarden. Bulletin d'analyse phénoménologique, vol. VII, n. 2, p. 1-35, 2011.

MITSCHERLING, J. Roman Ingarden's Ontology and Aesthetics. Ottawa: University of Ottawa Press, 1997.

WACHTER, D. 2005. Roman Ingarden's Ontology: Existential Dependence, Substances, Ideas, and Other Things Empiricists Do Not Like. 
In: CHRUDZIMSKI, A. (ed.). Existence, Culture, and Persons: The Ontology of Roman Ingarden. Frankfurt: Ontos Verlag, p. 55-82. 